\title{
BIOLOGI REPRODUKSI IKAN SUMPIT (Toxotes microlepis Gunther 1860) DI PERAIRAN SUNGAI MUSI SUMATERA SELATAN
}

\section{BIOLOGY OF REPRODUCTION OF SMALL SCALE ARCHER FISH (Toxotes microlepis Gunther 1860) IN DOWNSTREAM OF MUSI RIVER, SOUTH SUMATERA}

\author{
Ni Komang Suryati, Safran Makmur dan Syarifa Nurdawati \\ Peneliti pada Balai Penelitian Perikanan Perairan Umum-Palembang \\ Teregistrasi I tanggal: 16 April 2014; Diterima setelah perbaikan tanggal: 17 November 2014; \\ Disetujui terbit tanggal: 19 November 2014 \\ Email: komang_nks@yahoo.com
}

\begin{abstract}
ABSTRAK
Kegiatan penangkapan ikan sumpit sebagai ikan hias secara terus menerus di Sungai Musi oleh para nelayan akan mengakibatkan penurunan populasi ikan tersebut. Ikan sumpit termasuk ikan yang bernilai ekonomis tinggi, harganya di pasaran Rp 150.000,-. Oleh karena itu perlu dilakukan penelitian untuk mengetahui aspek biologi reproduksi ikan sumpit sebagai salah satu informasi untuk mendukung pelestarian ikan sumpit agar populasi ikan sumpit tetap terjaga. Penelitian dilakukan pada setiap bulan sejak Juni hingga Oktober 2011. Pengambilan sampel Ikan sumpit dilaksanakan di Perairan Sungai Musi dari Borang sampai Sungsang. Hasil penelitian menunjukkan rasio kelamin antara ikan jantan dan ikan betina terjadi ketidakseimbangan dimana rasio kelamin ikan jantan jauh lebih banyak dibandingkan rasio kelamin ikan betina (2:1). Rata-rata nilai Indeks Gonad Somatik ikan sumpit berkisar antara 4,27 $\pm 1,27$. Nilai dari fekunditas ikan sumpit betina secara keseluruhan berkisar 6.655-72.726 butir/individu. Kisaran diameter telurnya antara 0,27 - 0,95 mm. Ukuran pertama kali matang gonad pada panjang total 134,97 mm untuk ikan jantan dan 116,31 mm untuk ikan betina.
\end{abstract}

KATA KUNCI: Biologi reproduksi, ikan sumpit, Sungai Musi

\begin{abstract}
Fishing activity of archer fish as ornamental fish continuously in Musiriver by fisher will decrease it population. The price is Rp 150.000,-/fish in market so that Archer fish has high economy value. Therefore it was necessary to study the reproductive biology of archerfish that may be used as a reference for better management in order to achieve stability of its population. The research was conducted every month from June to October 2011 in downstream of Musiriver South Sumatera. Result of this research showed that proportion between male and female were not equal (2:1). Gonad Somatic Index of archer fish values ranged 4,27 $\pm 1,27$ and the fecundity of the female is estimated between 6655 to 72726 eggs. The average diameter of mature egss ranged form 0.27 to $0.95 \mathrm{~mm}$. Length of first maturity for male and female were $134.97 \mathrm{~mm}$ and $116.31 \mathrm{~mm}$, respectivelly.
\end{abstract}

KEYWORDS: Biology reproduction, archerfish, Musi River

\section{PENDAHULUAN}

Ikan sumpit (Toxotes microlepis Gunther,1860) merupakan salah satu jenis ikan yang hidup di perairan Sungai Musi, Sumatera Selatan. Ikan sumpit adalah salah satu ikan yang bernilai ekonomis tinggi sebagai ikan hias, di pasaran harga ikan ini yang berukuran $10 \mathrm{~cm}$ bisa mencapai Rp 150.000,- per ekor. Hal ini merupakan salah satu penyebab ikan sumpit menjadi sasaran dalam kegiatan perikanan tangkap bagi nelayan di perairan Sungai Musi. Selanjutnya berdasarkan hasil wawancara di lapangan melaporkan bahwa para nelayan dapat menangkap ikan sumpit 100-200 ekor per bulannya jika mendapatkan pesanan, penangkapan secara terus menerus dapat berdampak pada menurunnya populasi ikan sumpit.
Kegiatan penangkapan ikan sumpit secara terus menerus di Sungai Musi oleh para nelayan, akan mengakibatkan penurunan populasi ikan tersebut karena ikan yang tertangkap terdiri dari berbagai ukuran sehingga dapat mempengaruhi kelestarian stok yang terdapat di alam. Selanjutnya Saputra et al. (2009), menyatakan apabila hasil tangkapan didominasi ikan yang berukuran terlalu kecil maka akan mengakibatkan lebih-tangkap saat masa pertumbuhan, sedangkan apabila ikan yang tertangkap sebagian besar merupakan ikan yang matang gonad maka akan terjadi lebih-tangkap saat proses rekrutmen. Oleh karena itu perlu dilakukan penelitian untuk mengetahui aspek biologi reproduksi ikan sumpit sebagai salah satu informasi untuk mendukung pelestarian ikan sumpit agar populasinya di alam tetap terjaga. 


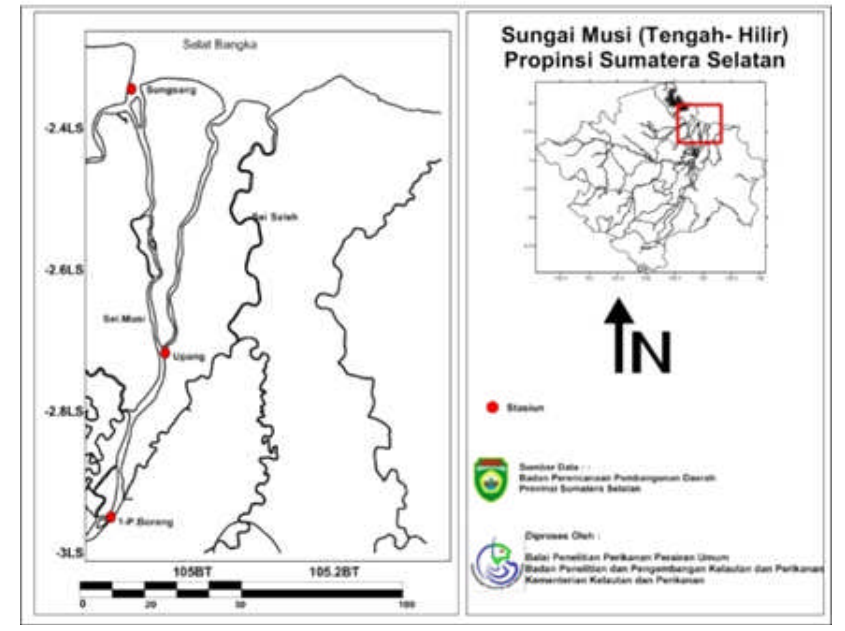

Gambar 1. Peta lokasi penelitian ikan sumpit.

Picture 1. Sampling site of smallscale archerfish.

Tabel 1. Morfologi tingkat kematangan gonad ikan sumpit

Table 1. Morphology gonad maturity stage of smallscale archerfish

\begin{tabular}{|c|c|c|}
\hline $\begin{array}{c}\text { TKG/ } \\
\text { Maturity stage }\end{array}$ & Jantan/Male & Betina/Female \\
\hline I & $\begin{array}{l}\text { Gonad kecil, warna merah jernih, } \\
\text { bentuk memanjang. }\end{array}$ & $\begin{array}{l}\text { Gonad masih kecil, memanjang, warna merah muda, } \\
\text { permukaan licin. }\end{array}$ \\
\hline II & $\begin{array}{l}\text { Ukuran gonad lebih besar dan lebih } \\
\text { panjang, warna putih kemerahan. }\end{array}$ & $\begin{array}{l}\text { Ukurannya lebih besar dari TKG I, warna gelap } \\
\text { kekuning-kuningan, telur belum dapat terlihat jelas } \\
\text { oleh mata telanjang, bentuk mulai melebar. }\end{array}$ \\
\hline III & $\begin{array}{l}\text { Gonad lebih besar dibandingkan TKG } \\
\text { II, warna merah pekat, permukaan agak } \\
\text { berlekuk. }\end{array}$ & $\begin{array}{l}\text { Warna gonad kuning kemerahan, telur sudah mulai } \\
\text { kelihatan dengan jelas dengan mata, namun telur masih } \\
\text { sulit dipisah-pisahkan. }\end{array}$ \\
\hline IV & $\begin{array}{l}\text { Gonad semakin panjang dan pejal. } \\
\text { Warna merah pucat. }\end{array}$ & $\begin{array}{l}\text { Gonad semakin besar, warna kuning cerah, telur sudah } \\
\text { mudah dipisah-pisahkan, butir-butir telur kelihatan } \\
\text { lebih besar dari TKG III }\end{array}$ \\
\hline $\mathbf{V}$ & Tidak ditemukan sampel & $\begin{array}{l}\text { Gonad sudah kempis dan mengkerut, warna kuning } \\
\text { keruh, terdapat butir-butir telur pada ujung pelepasan }\end{array}$ \\
\hline
\end{tabular}

\section{BAHANDANMETODE}

\section{Waktu dan Lokasi Penelitian}

Penelitian dilakukan setiap bulan sejak Juni hingga Oktober 2011 di perairan bagian hilir Sungai Musi Sumatera Selatan. Lokasi penelitian yang dipilih meliputi wilayah Borang hingga Sungsang yang dianggap mewakili wilayah bagian hilir Sungai Musi (Gambar 1).

\section{Pengumpulan Data}

Pengambilan sampel ikan sumpit menggunakan alat tangkap belat dan jaring kantong. Setelah didapatkan sampel ikan sumpit kemudian diukur panjang (ketelitian $0,1 \mathrm{~cm}$ ) dan bobotnya (ketelitian 0,1 gram). Selanjutnya contoh ikan dibedah menggunakan disecting set. Contoh gonad diawetkan dengan formalin $10 \%$ dan khusus untuk pengamatan fekunditas diawetkan dengan menggunakan larutan gilson. Pengamatan sample gonad dilakukan di Laboratorium Balai Penelitian Perikanan Perairan Umum.

\section{Analisis Data}

Ikan sumpit yang diperoleh selama penelitian berjumlah 252 ekor yang terdiri dari 177 ekor ikan jantan dan betina 65 ekor. Jumlah gonad yang masak pada ikan sumpit betina pada TKG IV berjumlah 14 gonad. Dari 14 gonad tersebut diambil 50 butir pada masing-masing bagian posterior, median dan anterior.

TKG diamati secara visual dengan cara melihat perubahan morfologi. Pengamatan morfologi ikan jantan berbeda dengan ikan betina (Tabel 1). Effendie (1979), bahwa untuk ikan betina yang diamati adalah bentuk, ukuran, warna, kehalusan, pengisian ovarium dalam rongga tubuh serta ukuran, kejelasan bentuk dan warna telur dalam ovarium. Sedangkan untuk ikan jantan yang 
diamati adalah bentuk, ukuran, warna dan pengisian testis dalam rongga tubuh serta keluar tidaknya cairan dari testis (keadaan segar).

Untuk mengetahui perbandingan jenis kelamin ikan contoh dilakukan uji Chi - kuadrat sebagai berikut :

$\mathrm{X}^{2}=\sum \frac{\mathrm{oi}-\mathrm{ei}}{\mathrm{ei}}$

Di mana :

$\mathrm{X}^{2}=$ distribusi kelamin

$o i=$ pengamatan ikan ke- $i$

$e i=$ harapan $\mathrm{ke}-\mathrm{i}$

Fekunditas dihitung dengan menggunakan metode gravimetrik yaitu dengan cara mengambil sub contoh bobot gonad dengan rumus (Bagenal, 1978) :

$\mathrm{F}=\frac{\mathrm{G}}{\mathrm{Q}} \times \mathrm{N}$

Keterangan :

$\mathrm{F}$ = fekunditas total (butir)

$\mathrm{G}=$ bobot gonad total $(\mathrm{g})$

$\mathrm{Q}=$ bobot gonad contoh $(\mathrm{g})$

$\mathrm{N}$ = jumlah telur pada gonad contoh (butir)

Untuk pengamatan diameter telur masing-masing bagian sampel gonad tersebut diambil butir telurnya dengan jumlah total 150 butir telur, setelah itu diamati menggunakan mikroskop yang dilengkapi dengan mikrometer okuler.

Indeks Kematangan Gonad ditentukan dengan menggunakan rumus menurut Effendie (1979) sebagai berikut:

Indek Kematangan Gonad $=\frac{\text { Berat Gonad }(\text { gram })}{\text { Berat Tubuh }(\text { gram })} \times 100 \%$

Pendugaan panjang pertama kali matang gonad (Length of first maturity) dilakukan sesuai dengan prosedur penghitungan yang dilakukan oleh Udupa (1986):

$$
m=X k+\frac{x}{2}-\left(X \sum P_{i}\right)
$$

Keterangan:

$\mathrm{m}=\log$ ukuran ikan saat pertama kali matang gonad

$\mathrm{Xk}=\log$ ukuran ikan dimana $100 \%$ ikan sampel sudah matang

$\mathrm{X}=$ selang log ukuran

$\mathrm{Pi}=$ proporsi ikan matang gonad pada kelompok ke-i

Rata-rata ukuran pertama matang gonad diperoleh dari nilai $\operatorname{antilog}(\mathrm{m})$.

\section{HASIL DAN BAHASAN}

HASIL

Rasio Kelamin

Ikan Sumpit yang diperoleh selama penelitian berjumlah 252 ekor yang terdiri dari 177 ekor ikan jantan dan betina 65 ekor. Hasil penelitian menunjukkan rasio kelamin antara jantan dan betina sebesar 2:1. Hal ini didukung dari hasil uji Chi-squre terhadap rasio kelamin ikan sumpit secara keseluruhan berdasarkan selang kelas panjang total pada taraf nyata 0,05 didapatkan bahwa rasio kelamin ikan sumpit di Sungai Musi dalam kondisi yang tidak seimbang karena hasilnya adalah $X^{2}$ hitung $>X^{2}$ tabel $(77,97>15,51)$.

\section{Tingkat Kematangan Gonad}

Tingkat kematangan gonad (TKG) ikan sumpit (Toxotes microlepis Gunther,1860) baik jantan maupun betina ditentukan melalui pengamatan secara morfologi (Tabel. 1). Jumlah Ikan sumpit (Tabel. 2) yang paling banyak ditemukan berada pada TKG 1 untuk jantan sebanyak 119 ekor dan TKG 2 untuk betina sebanyak 26 ekor. Sedangkan ikan betina TKG 4 berjumlah 13 ekor dan jantan 3 ekor. Hanya terdapat satu ekor ikan sumpit betina yang berada pada TKG V yang dicirikan dengan gonad sudah kempis dan mengkerut, warna kuning keruh, terdapat butir-butir telur pada ujung anus.

\section{Indeks Kematangan Gonad}

Di dalam proses reproduksi sebelum terjadi pemijahan, sebagian besar hasil metabolisme tertuju untuk perkembangan gonad. Untuk mengetahui perubahan yang terjadi di dalam gonad secara kuantitatif dapat dinyatakan dengan suatu indeks yang dinamakan Indeks Kematangan Gonad (IKG). Hasil penelitian pada semua bulan dan stasiun pengamatan menunjukkan rata-rata nilai Indeks Kematangan Gonad ikan sumpit berkisar antara 4,27 $\pm 1,27$ (Gambar. 2). Nilai Indeks Kematangan Gonad semakin meningkat seiring dengan bertambahnya TKG hingga ke TKG 4. Pada TKG 5 terjadi penurunan IKG karena pada tahap tersebut telur yang terdapat di dalam gonad sudah berkurang.

\section{Fekunditas}

Nilai dari fekunditas ikan sumpit betina pada Tingkat Kematangan Gonad IV yang didapatkan selama penelitian pada dua bulan pengambilan sampel secara keseluruhan berkisar 6.655-72.726 butir/individu. Nilai fekunditas terkecil terdapat pada ikan yang berat badannya $41 \mathrm{~g}$ dan yang tertinggi terdapat pada ikan dengan berat $102 \mathrm{~g}$. Jumlah ini relatif lebih kecil dibandingkan dengan 
fekunditas Toxotes chatareus antara 38.354 hingga 147.185 butir dengan panjang total yang berkisar antara 14,5 hingga 22,5 cm dan berat total 48,7 hingga 270,2 g, dan Toxotes jaculatrix 25.251 hingga 150.456 butir dengan panjang total berkisar antara 12,2 hingga $23,0 \mathrm{~cm}$ dan berat total 25,7 hingga 275,0 g di Pantai Johor Malaysia (Simon, et al., 2012). Grafik hubungan antara fekunditas dengan panjang dan bobot ikan sumpit menunjukan bahwa semakin berat bobot dan panjang ikan maka semakin meningkat fekunditasnya (Gambar. 3).

Tabel 2. Tingkat kematangan gonad ikan sumpit

Table 2. Gonad maturity stage of smallscale archerfish

\begin{tabular}{cccccc|ccccc}
\hline $\begin{array}{c}\text { Selang kelas panjang/ } \\
\begin{array}{c}\text { Range total lenght, class } \\
\text { total (mm) }\end{array}\end{array}$ & \multicolumn{3}{c}{ Betina/Female } & \multicolumn{5}{c}{ Jantan/Male } \\
& I & II & III & IV & V & I & II & III & IV & V \\
\hline $75-87$ & 0 & 0 & 0 & 0 & 0 & 7 & 1 & 0 & 0 & 0 \\
$88-100$ & 0 & 1 & 0 & 0 & 0 & 19 & 2 & 0 & 0 & 0 \\
$101-113$ & 2 & 0 & 0 & 0 & 0 & 33 & 7 & 2 & 0 & 0 \\
$114-126$ & 7 & 10 & 3 & 0 & 0 & 35 & 12 & 1 & 0 & 0 \\
$127-139$ & 3 & 10 & 9 & 6 & 0 & 18 & 18 & 1 & 1 & 0 \\
$140-152$ & 4 & 4 & 6 & 3 & 1 & 6 & 3 & 5 & 1 & 0 \\
$153-165$ & 0 & 1 & 1 & 2 & 0 & 1 & 2 & 1 & 1 & 0 \\
$166-178$ & 0 & 0 & 0 & 0 & 0 & 0 & 0 & 0 & 0 & 0 \\
$179-191$ & 0 & 0 & 0 & 2 & 0 & 0 & 0 & 0 & 0 & 0 \\
\hline Jumlah & 16 & 26 & 19 & 13 & 1 & 119 & 45 & 10 & 3 & 0 \\
\hline
\end{tabular}

Keterangan : Data merupakan gabungan dari semua titik dan bulan sampling

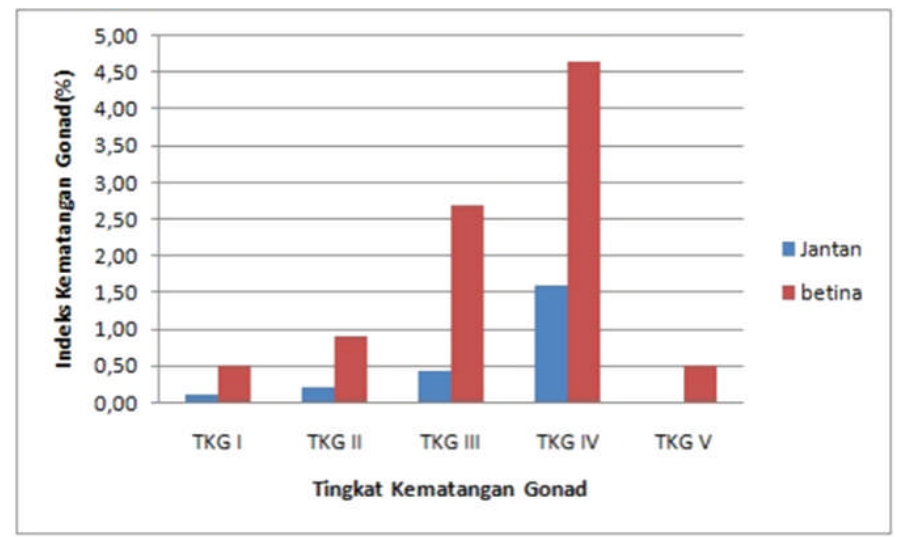

Gambar2. Indeks kematangan gonad ikan sumpit.

Figure 2. Gonad maturity index of smallscale archer fish.
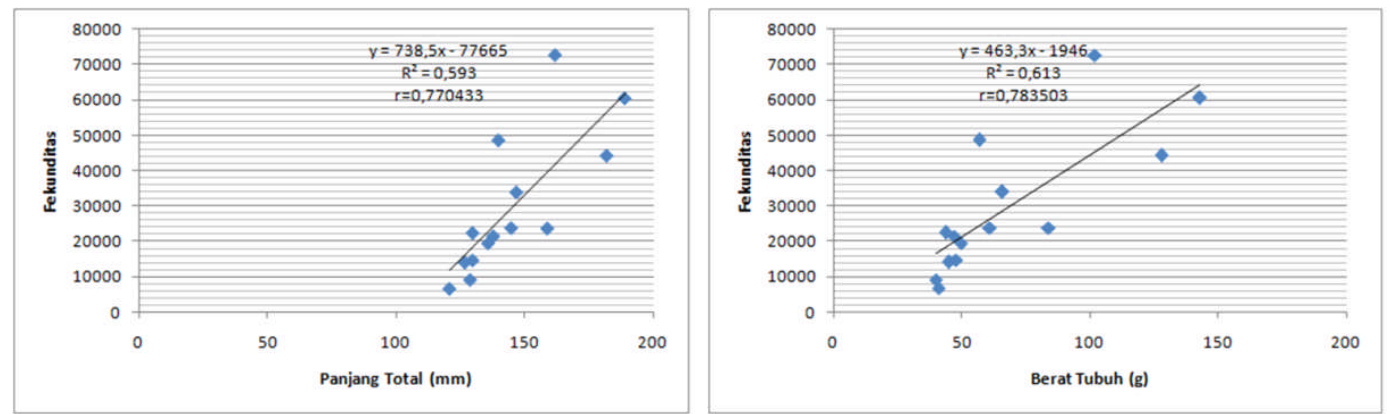

Gambar 3. Hubungan antara fekunditas dengan panjang dan bobot ikan sumpit.

Figure 3. Relationship between fecundity and length-weight of smallscale archer fish. 


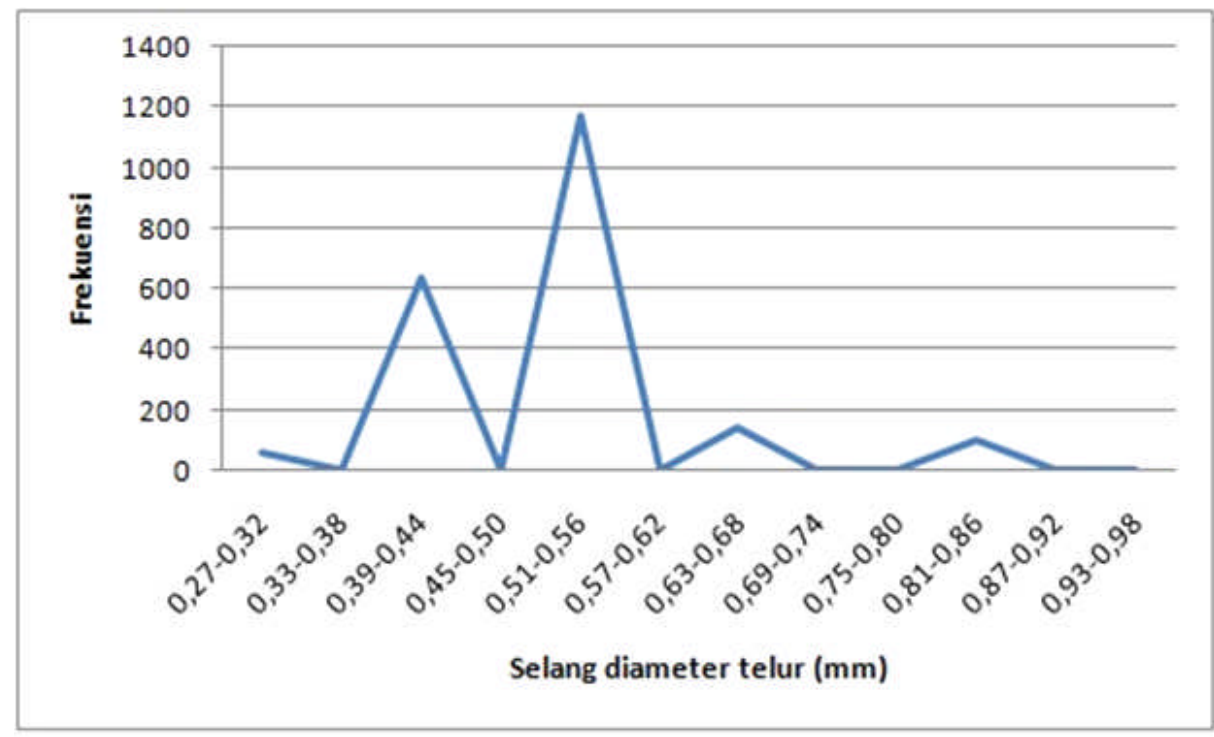

Gambar 4. Sebaran diameter telur ikan sumpit.

Figure 4. Eggs diameter distribution of smallscale archer fish.

Tabel 3. Ukuran pertama kali matang gonad ikan sumpit jantan

Table 3. $\quad$ Length of first maturity $(\mathrm{Lm})$ of male smallscale archer fish

\begin{tabular}{|c|c|c|c|c|c|c|c|c|c|}
\hline Class (mm) & $\begin{array}{l}\text { midlength } \\
\text { (ML) }\end{array}$ & $\begin{array}{l}\text { Log } \\
\text { Midlength } \\
\text { (Xi) }\end{array}$ & $\begin{array}{l}\text { No.of fish } \\
\text { sampled } \\
\text { (ni) }\end{array}$ & $\begin{array}{c}\text { No.of } \\
\text { immature } \\
\text { fish }(1,2,3)\end{array}$ & $\begin{array}{c}\text { No.of } \\
\text { mature fish } \\
(4,5)(r i)\end{array}$ & $\begin{array}{c}\text { Proportion } \\
\text { of Mature } \\
\text { fish (pi) }\end{array}$ & $\mathbf{X}=\mathbf{X} \mathbf{i} \mathbf{i}-\mathbf{X} \mathbf{i}$ & $q i=1-p i$ & $p i^{*} q i /(n i-1)$ \\
\hline $75-87$ & 81 & 1.908485 & 0 & 8 & 0 & 0 & 0.0646428 & 1 & 0 \\
\hline $88-100$ & 94 & 1.973128 & 1 & 21 & 0 & 0 & 0.0562559 & 1 & 0 \\
\hline $101-113$ & 107 & 2.029384 & 2 & 42 & 0 & 0 & 0.0497975 & 1 & 0 \\
\hline $114-126$ & 120 & 2.079181 & 20 & 48 & 0 & 0 & 0.0446704 & 1 & 0 \\
\hline $127-139$ & 133 & 2.123852 & 28 & 37 & 1 & 0.04 & 0.0405012 & 0.9643 & 0.0012755 \\
\hline $140-152$ & 146 & 2.164353 & 18 & 14 & 1 & 0.06 & 0.0370443 & 0.9444 & 0.0030864 \\
\hline $153-165$ & 159 & 2.201397 & 4 & 4 & 1 & 0.25 & 0.0341313 & 0.75 & 0.0625 \\
\hline $166-178$ & 172 & 2.235528 & 0 & 0 & 0 & 0.00 & 0.0316433 & 1 & 0 \\
\hline $179-191$ & 185 & 2.267172 & 2 & 0 & 0 & 0.00 & 0.0294935 & 1 & 0 \\
\hline $192-104$ & 198 & 2.296665 & 0 & 0 & 0 & 0.00 & & & 0 \\
\hline \multirow[t]{4}{*}{ total } & & & 75 & 174 & 3 & 0.34126984 & & 8.6587 & 0.0668619 \\
\hline & & & & & & & & & \\
\hline & & m & 2.13022857 & & & & & & \\
\hline & & $\mathrm{M}=$ antilog $\mathrm{m}$ & 134.967304 & & & & & & \\
\hline
\end{tabular}

Tabel 4. Ukuran pertama kali matang gonad ( $\mathrm{Lm}=$ Length of first maturity) ikan sumpit betina Table 4. Length of first maturity ( $\mathrm{Lm}$ ) of female smallscale archer fish

\begin{tabular}{|c|c|c|c|c|c|c|c|c|c|}
\hline $\begin{array}{l}\text { Class } \\
(\mathbf{m m})\end{array}$ & $\begin{array}{l}\text { midlength } \\
\text { (ML) }\end{array}$ & $\begin{array}{c}\text { Log Midlength } \\
\text { (Xi) }\end{array}$ & $\begin{array}{c}\text { No.of fish } \\
\text { sampled (ni) }\end{array}$ & $\begin{array}{c}\text { No.of } \\
\text { immature } \\
\text { fish }(\mathbf{1}, \mathbf{2}, \mathbf{3})\end{array}$ & \begin{tabular}{|c|} 
No.of \\
mature fish \\
$(4,5)(r i)$
\end{tabular} & $\begin{array}{c}\text { Proportion } \\
\text { of Mature } \\
\text { fish (pi) }\end{array}$ & $\begin{array}{c}\mathbf{X}=\mathbf{X i i}- \\
\mathbf{X i}\end{array}$ & $q \mathbf{i}=\mathbf{1}-\mathbf{p i}$ & $p i^{*} q i /(n i-1)$ \\
\hline $75-87$ & 81 & 1.908485019 & 0 & 0 & 0 & 0 & 0.0646 & 1 & 0 \\
\hline $88-100$ & 94 & 1.973127854 & 1 & 1 & 0 & 0 & 0.0563 & 1 & 0 \\
\hline $101-113$ & 107 & 2.029383778 & 2 & 2 & 0 & 0 & 0.0498 & 1 & 0 \\
\hline $114-126$ & 120 & 2.079181246 & 20 & 20 & 0 & 0 & 0.0447 & 1 & 0 \\
\hline $127-139$ & 133 & 2.123851641 & 28 & 22 & 6 & 0.21 & 0.0405 & 0.7857 & 0.00623583 \\
\hline $140-152$ & 146 & 2.164352856 & 18 & 14 & 4 & 0.22 & 0.037 & 0.7778 & 0.01016703 \\
\hline $153-165$ & 159 & 2.201397124 & 4 & 2 & 2 & 0.50 & 0.0341 & 0.5 & 0.08333333 \\
\hline $166-178$ & 172 & 2.235528447 & 0 & 0 & 0 & 0.00 & 0.0316 & 1 & 0 \\
\hline 179-191 & 185 & 2.267171728 & 2 & 0 & 2 & 1.00 & 0.0295 & 0 & 0 \\
\hline $192-104$ & 198 & 2.29666519 & 0 & 0 & 0 & 0.00 & & & 0 \\
\hline \multirow[t]{4}{*}{ Total } & & & 75 & 61 & 14 & 1.93650794 & & 7.0635 & 0.09973619 \\
\hline & & & & & & & & & \\
\hline & & $\mathrm{m}$ & 2.065621429 & & & & & & \\
\hline & & $\mathrm{M}=$ antilog $\mathrm{m}$ & 116.3111711 & & & & & & \\
\hline
\end{tabular}




\section{Diameter Telur}

Telur ikan sumpit berbentuk bulat seperti telur ikan pada umumnya. Kisaran diameter telurnya antara 0,27-0,95 $\mathrm{mm}$. Jumlah terbanyak terdapat pada selang kelas $0,51-$ $0,56 \mathrm{~mm}$ yaitu berjumlah 1.169 butir dan diameter terkecil terdapat pada selang kelas 0,93-0,98 mm yang berjumlah hanya 1 butir (Gambar. 4). Sebaran diameter telur ikan sumpit terlihat beragam (heterogen) karena memiliki beberapa puncak.

\section{Ukuran Pertama Kali Matang Gonad}

Berdasarkan analisis dengan metode Spearman-Karber (Tabel 3 dan 4) diperoleh rata-rata ukuran pertama kali matang gonad pada panjang total $134,97 \mathrm{~mm}$ pada selang kelas 127-139 mm untuk ikan jantan dan panjang total $116,31 \mathrm{~mm}$ pada selang kelas 114-126 mm untuk ikan betina. Nilai ini menjadi indikasi bahwa ikan sumpit betina lebih cepat matang gonad dari pada ikan jantan.

\section{BAHASAN}

Bal \& Rao (1984) menyatakan bahwa perbandingan antara ikan jantan dan betina yang ideal dalam satu populasi adalah 1:1. Menurut Sadhatomo \& Potier (1991) dalam Saputra (2009), bahwa perbandingan jenis kelamin ikan diharapkan seimbang $(1: 1)$ bahkan jumlah betina lebih banyak dibandingkan jantan sehingga populasinya dapat dipertahankan walaupun ada kematian alami atau penangkapan. Rasio kelamin ikan sumpit jantan dan betina sebesar 2: 1 menunjukan bahwa terjadi ketidakseimbangan dimana rasio kelamin ikan jantan jauh lebih banyak dibandingkan rasio kelamin ikan betina. Hal ini serupa dengan hasil penelitian T.chatareus dan T.jaculatrix di perairan pantai Johor Malaysia (Simon et al., 2012) dengan proporsi jantan terhadap betina sebesar 3:1. Ketidakseimbangan tersebut dapat disebabkan karena perbedaan pola distribusi, ketersediaan makanan, kepadatan populasi, dan keseimbangan rantai makanan. Hal ini sesuai dengan pernyataan Kiat (2004) dalam Haryono (2006) bahwa ketidakseimbangan rasio kelamin jenis ikan air payau seperti ikan sumpit dapat disebabkan oleh kepadatan populasi dan kondisi perairan serta perbedaan tingkah laku.

Sejalan dengan perkembangan gonad, IKG ikan akan semakin bertambah besar dan akan mencapai batas kisaran maksimum pada saat akan terjadi pemijahan (Effendie, 1979). Nilai IKG ikan sumpit di Sungai Musi bagian hilir selama penelitian yaitu 4,27 $\pm 1,27$, hasil ini relative lebih tinggi dibandingkan T.chatareus dengan nilai (IKG) sebesar 1,061 $\pm 0,075$ dan T.jaculatrix sebesar 1,796 $\pm 0,077$ di perairan pantai Johor Malaysia (Simon et al., 2009). Berdasarkan kisaran nilai IKG tersebut maka diduga ikan sumpit dapat memijah lebih dari satu kali setiap tahunnya. Hal ini sesuai dengan pendapat Bagenal (1978) bahwa ikan yang mempunyai nilai IKG lebih kecil dari $20 \%$ dapat memijah lebih dari satu kali setiap tahun. Sepanjang tahun dapat terjadi adanya puncak musim pemijahan. Peningkatan nilai IKG juga dapat menjadi indikasi peningkatan aktivitas reproduksi.

Dalam usaha eksploitasi sumberdaya perikanan, pengetahuan fekunditas dapat digunakan untuk mengetahui potensi reproduksi suatu stok ikan tertentu serta kelulushidupan telur dan penambahan baru (recruitment) sebagai hasil pemijahan pertahun (Rahardjo et al., 2011). Hasil regresi dari fekunditas dengan panjang total dan bobot tubuh ikan, didapatkan nilai dari koefisien korelasi antara hubungan Fekunditas dengan panjang total bernilai 0,770 dan dengan berat tubuh bernilai 0,783 ini berarti korelasi antar keduanya sangat erat, mengartikan bahwa diduga ukuran panjang total dan berat tubuh ikan sumpit mempengaruhi jumlah fekunditas dari ikan ini. Hal ini sesuai dengan Rahardjo et al. (2011) yang menyatakan bahwa fekunditas ikan biasanya meningkat seiring dengan pertambahan bobot dan panjang. Dari nilai korelasi antara fekunditas dan panjang total serta berat tubuh ikan dapat disimpulkan bahwa fekunditas ikan sumpit lebih berhubungan dengan berat tubuh ikan karena nilai koefisien korelasi dari berat tubuh lebih mendekati angka satu dibandingkan dengan panjang total. Hal ini berbeda dengan pernyataan Effendie (2002) bahwa fekunditas lebih sering dihubungkan dengan panjang dari pada berat, karena panjang penyusutannya lebih kecil dibandingkan dengan berat yang dapat dengan mudah berkurang apabila terjadi perubahan lingkungan dan kondisi fisiologis pada ikan.

Nikolskii (1963) menjelaskan bahwa salah satu parameter untuk menentukan potensi reproduksi adalah dengan mengetahui variasi diameter telur pada ovary. Diameter telur dipengaruhi oleh jumlah makanan pada ikan betina untuk proses metabolisme. Sebaran diameter telur mencerminkan tipe pemijahan ikan. Sebaran diameter telur ikan sumpit terlihat beragam (heterogen) karena memiliki beberapa puncak sehingga menunjukkan tipe pemijahan ikan sumpit yaitu termasuk pemijah bertahap (partial spawner). Hal ini sesuai dengan pernyataan Effendie (2002) bahwa pada ikan dan avertebrata sering dijumpai distribusi diameter telur bimodal atau dua modus, yaitu modus pertama terdiri dari telur belum matang gonad dan modus kedua terdiri dari telur yang matang gonad. Hal ini 
menunjukkan suatu strategi ikan pada umumnya untuk memelihara kelangsungan hidup keturunannya dan mempertahankan populasinya yang dicirikan dengan telur pelagic berukuran kecil dan dalam jumlah yang banyak serta tanpa adanya pengasuhan dari induk (Simon et al., 2012). Diameter telur berhubungan dengan fekunditasnya. Biasanya semakin besar diameter telur maka semakin kecil fekunditas yang dihasilkan. Semakin besar ukuran diameter telur akan semakin baik, karena dalam telur tersebut tersedia cadangan makanan yang berupa kuning telur sebagai sumber energi sehingga larva ikan akan dapat bertahan lebih lama sebelum memperoleh makanan dari luar.

Berdasarkan nilai ukuran pertama kali matang gonad yang diperoleh selama penelitian maka ikan sumpit betina lebih cepat matang gonad dibandingkan dengan ikan sumpit jantan. Ukuran pertama kali matang gonad merupakan salah satu aspek biologi yang penting diketahui sebagai dasar pengelolaan, dimana pada panjang ukuran tertentu harus membiarkan sejumlah ikan agar proses perkembangbiakan terjadi sehingga kelestarian sumber dayanya dapat terjaga. Ukuran panjang pertama kali matang gonad sangat bervariasi diantara jenis ikan maupun dalam jenis ikan itu sendiri, dengan demikian individu yang berasal dari satu kelas umur ataupun dari kelas panjang yang sama tidak selalu harus mencapai panjang pertama kali matang gonad pada ukuran yang sama (Udupa, 1986).

\section{KESIMPULAN}

1. Pada saat penelitian rasio kelamin ikan sumpit (Toxotes microlepis Gunther,1860) jantan dan betina, secara keseluruhan berada dalam keadaan yang tidak ideal $(2: 1)$.

2. Berdasarkan kisaran nilai IKG diduga ikan sumpit dapat memijah lebih dari satu kali setiap tahunnya.

3. Sebaran diameter telur ikan sumpit terlihat beragam (heterogen) karena memiliki beberapa puncak sehingga menunjukkan tipe pemijahan ikan sumpit yaitu termasuk pemijah bertahap (partial spawner).

4. Berdasarkan ukuran pertama kali matang gonad menunjukkan ikan sumpit betina lebih cepat matang gonad dibandingkan dengan ikan sumpit jantan.

\section{SARAN}

Agar populasi ikan sumpit di perairan Sungai Musi tetap terjaga maka diharapkan aktivitas penangkapan dilakukan dengan menggunakan alat tangkap yang lebih selektif terhadap ikan sumpit yang memiliki ukuran panjang di atas ukuran pertama kali matang gonad, sehingga memberikan kesempatan bagi populasi ikan sumpit untuk beregenerasi.

\section{DAFTAR PUSTAKA}

Bagenal, T. 1978. Method for Assessment of Fish Production in Fresh Waters. Third edition. IBP Handbook No 3. Blackwell Scientific Publication. Oxford: 365 p.

Bal, D.V \& K.V. Rao. 1984. Marine Fisheries, Tara McGraw-Hill Publishing Company Limited. New Delhi: 470 hal.

Effendie, M.I. 1979. Metode Biologi Perikanan. Penerbit Yayasan Dewi Sri. Bogor.

Effendie, M.I. 2002. Biologi Perikanaan. Yayasan Pustaka Nusatama. Yogyakarta: 163 hal.

Haryono. 2006. Aspek biologi ikan tambra (Tor tambroides Blkr.) yang eksotik dan langka sebagai dasar domestikasi. Biodiversitas. 7 (2): 195-198.

Nikolskii, G.V. 1963. Fish population dynamics oliver and boyd. Edinburg: 323p.

Rahardjo, M.F., S.S Djadja, A. Ridwan \& Sulistiono. 2011. Iktiologi. Lubuk Agung, Bandung. 394 p.

Saputra, S.W., S. Prijadi \& A.S. Gabriela .2009. Beberapa aspek biologi ikan kuniran (Upeneus Spp) di Perairan Demak. Jurnal Saintek Perikanan. Universitas Diponogoro Semarang. $5(1): 1-6$.

Simon, K.D., Y. Bakar., A. Samat., C.C. Saidi., A. Azis \& A.G. Mazlan. 2009. Population growth, trophic level, and reproductive Biology of two congeneric archer fishes (Toxotes chatareus, Hamilton 1822 and Toxotes jaculatrix, Pallas 1767) inhabiting Malaysian Coastal Waters. Journal of Zhejiang University SCIENCE B. Volume 10: 902-911.

Simon, K.D., Y. Bakar, A.G. Mazlan, C.C. Zaidi, A Samat, A Arshad, S.E. Temple, \& NJ BrownPeterson. 2012. Aspects of the reproductive 
biology of two archer fishes Toxotes chatareus (Hamilton,1822) and Toxotes jaculatrix (Pallas, 1767). Environmental biology of fishes. 93 (4): 491-503.
Udupa, K.S. 1986. Statistical method of estimating the size at first maturity of fishes. Fishbyte. 4 (2):8-10. 